\title{
Dual Axis Shadow Tracker
}

\author{
A.K. Dey, JVR Nickey and Yanxia Sun \\ ${ }^{1}$ Process Energy and Environmental Technology Station, University of Johannesburg, South Africa \\ ${ }^{2}$ Electrical \& Electronics Department, University of Johannesburg, South Africa
}

\begin{abstract}
Solar automatic fire tracker \& extinguisher system is a new innovation technology and designed by our technology station (Process, Energy and Environmental Technology Station, University of Johannesburg) in combination with the characteristic of heat $\&$ fire detection apparatus. This industrial automation fire extinguisher have a platform with 90 degree of freedom and the DC motor base wheel will be passive or active, fixed or steerable according to system logic control unit to target a fire source. To get the system more effective and flexible the wheel will regulate with two characteristics: 1 . Wheel spinning, 2. driving control. The whole system will operate by Solar energy source because it can be use in remote areas where it is too difficult to extend the electricity power grid connection to the fire extinguisher (solar extinguisher is not fix unit, it will always travel from one place to another place to find photon and detect flame). The most fun about the project is to watch him navigate from light source to light source trying desperately to stay alive. This character is the secondary operation when the battery status under the level of $60 \%$.
\end{abstract}

\section{Introduction}

Every industry working with combustible and toxic gases needs to have an understanding of the impact of the many hazards associated with fire. Proper fire detection solutions can be used to enable better situational analysis and more informed decision making during a fire event. Process and plant engineers in the oil and gas industry and a wide range of other hazardous process and manufacturing industries require continuous flame monitoring device \& fire extinguisher to prevent catastrophic fires [1].

\section{Modelling of the prototype}

This paper describes the design process and operation of an innovative technology is introduced two dimension shadow detection prototype for solar modules positioning by sensing the point of maximum brightness of the sun light with the building of a sensor based device and using a linear motion on horizontal (X-Y) coordinates. The entire system performs a continuous detection of the entire oil \& gas plant; allowing it to identify the brightest point of the plant, even with a large shadow around the prototype, and guiding the solar module to that point by using a two-axis drive system, and running a new bright place where battery can charge with full efficiency to reposition the solar module if the brightest point has changed its location. The data and signal processing of the fire detector sensor, proximate sensor and solar modules are performed by a microcontroller- based system. The energy obtained from the solar module is bigger and remains stable when the automatic shadow detection prototype is used. And the solar power systems applied in fire extinguisher device used fixed-mounted solar panels [2] [3]. One of the most important role of the prototype is to search sun light. And this light will charge the batteries through the solar panel to energise the whole system which will help to find out the real fire source. We installed four LDRs mounted in four side of the prototype to assistance him discover the brightest spot in the plant. The main program loop compares the values of the four resistors and moves toward the lightest source [4]. Once prototype discover the brightest spot (four of the resistor see the lightest source), will stop and charge the battery through the solar panel. HCRL-MC board used for controlling the prototype direction and speed regulation with sensors data communication. A touchscreen sends the processor MC9SO8MP16 target torque/velocity signals over the serial communication interface. Additional motor controllers communicate with the processor via inter-integrated circuit bus (I2C). The processor sends a pulse-width modulated voltage control signal to the DC motor in response to these inputs.

The top view of the prototype is below (figure-1) which is assume as an $\mathrm{X}-\mathrm{Y}$ axis solar shadow tracker. Four LDR sensors are placed adjacent to the top of the solar panel and will be triggered motor when shadow is detected [5]. An activate signal will be sent to the programmable logic controller and when the signal is received, the PLC output signal will trigger the driver and activate the wheal motor to rotate clockwise and anticlockwise under certain 
circumstances (to move the fire extinguisher forward and backword).

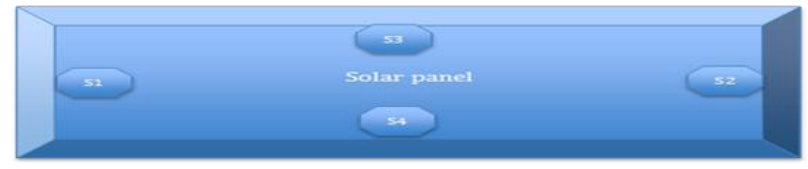

Figure 1. Top view of the prototype

Table 1. Condition for movement (direction)

\begin{tabular}{|l|l|l|l|l|}
\hline $\begin{array}{l}\text { Direction } \\
\text { of motion }\end{array}$ & $\begin{array}{l}\text { Active } \\
\text { Wheel } \\
\text { name }\end{array}$ & $\begin{array}{l}\text { Wheel } \\
\text { Rotation } \\
\text { direction }\end{array}$ & $\begin{array}{l}\text { Other wheel } \\
\text { condition }\end{array}$ & $\begin{array}{l}\text { Condition } \\
\text { for LDR } \\
\text { sensor }\end{array}$ \\
\hline $\begin{array}{l}\text { North } \\
\text { towards }\end{array}$ & $\begin{array}{l}\text { A \& B } \\
\text { wheel } \\
\text { motor } \\
\text { on }\end{array}$ & $\begin{array}{l}\text { Anti- } \\
\text { clockwise }\end{array}$ & $\begin{array}{l}\text { C \& D wheel } \\
\text { motor steady } \\
\text { state }\end{array}$ & $\begin{array}{l}\text { S4 sensor } \\
\text { under } \\
\text { shadow }\end{array}$ \\
\hline $\begin{array}{l}\text { South } \\
\text { towards }\end{array}$ & $\begin{array}{l}\text { C \& D } \\
\text { wheel } \\
\text { motor } \\
\text { on }\end{array}$ & clockwise & $\begin{array}{l}\text { A \& B wheel } \\
\text { motor steady }\end{array}$ & $\begin{array}{l}\text { S3 sensor } \\
\text { under } \\
\text { shadow }\end{array}$ \\
\hline $\begin{array}{l}\text { East } \\
\text { towards }\end{array}$ & $\begin{array}{l}\text { B \& D } \\
\text { wheel } \\
\text { motor } \\
\text { on }\end{array}$ & Clockwise & $\begin{array}{l}\text { A \& C wheel } \\
\text { motor steady } \\
\text { state }\end{array}$ & $\begin{array}{l}\text { S1 sensor } \\
\text { under } \\
\text { shadow }\end{array}$ \\
\hline $\begin{array}{l}\text { West } \\
\text { towards }\end{array}$ & $\begin{array}{l}\text { A \& C } \\
\text { wheel } \\
\text { motor } \\
\text { on }\end{array}$ & $\begin{array}{l}\text { Anti- } \\
\text { clockwise }\end{array}$ & $\begin{array}{l}\text { B \& D wheel } \\
\text { motor steady } \\
\text { state }\end{array}$ & $\begin{array}{l}\text { S2 sensor } \\
\text { under } \\
\text { shadow }\end{array}$ \\
\hline $\begin{array}{l}\text { A,B,C } \\
\text { state } \\
\text { position } \\
\text { \& D } \\
\text { wheel } \\
\text { motor } \\
\text { off } \\
\text { mode }\end{array}$ & $\begin{array}{l}\text { No } \\
\text { rotation } \\
\text { activity }\end{array}$ & $\begin{array}{l}\text { Stop } \\
\text { condition }\end{array}$ & $\begin{array}{l}\text { S1, S2, S3 } \\
\text { \& S4 } \\
\text { under } \\
\text { sunlight }\end{array}$ \\
\hline
\end{tabular}

The DC motor connect with gear shaft to turn wheal so that the LDR can move into the source of sunlight. On the other side fire detection sensor is connect to solenoid valve (SV) so detect fire and extinguish it by solenoid valve. Four proximate sensor (PS) monitoring systems used on the side of prototype to detect objects in the vicinity of the fire extinguisher and microcontroller give signal motor to move. Figure 2, shows the overall block diagram of the control system. The control process of the system is as follows: \# at the initial stage of the process, microcontroller reads the status of LDR sensors. \# after analysis the output value from four LDRs circuit, the W$\mathrm{S} 1$ sensor and E-S2 sensor will be compared. If $\mathrm{W}-\mathrm{S} 1$ is greater than E-S2 then move the wheel east side and vice versa. \# for shadow or cloudy weather condition the shadow tracking system will not move because there no difference values between four LDR sensors. \# the system checks the light via the LDR's, if its shadowiness stay more than 30 minutes the system automatically switches off the PLC with economic mode.

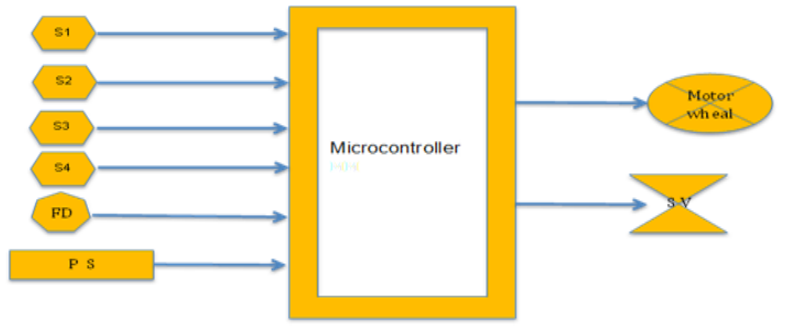

Figure 2. Overall control diagram for the prototype. ( $\mathrm{S}=$ sensor, $\mathrm{FD}=$ fire detection, $\mathrm{SV}=$ solenoid valve, $\mathrm{PS}=$ proximity sensor)

Four omnidirectional wheels are used to drive the prototype. Each wheel provides traction in the direction normal to the motor axis and parallel to the floor. The forces add up and provide a translational motion for the fire extinguisher. Omnidirectional wheels have choose for the project, because its allow them to drive on a straight path from a given location on the floor to another without having to rotate first [6]. Moreover, translational movement along any desired path can be combined with a rotation, so that the device arrives to its destination at the correct angle. Figure 3, shows the foundation of fire extinguisher.

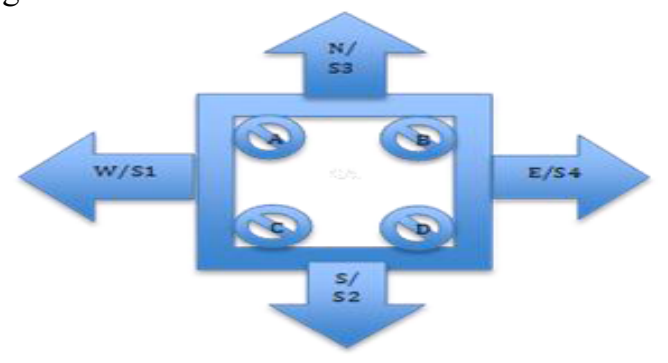

Figure 3. Foundation of prototype

\section{Work principle}

DC motor drive will follow the status of the LDR sensor. In $\mathrm{X}-\mathrm{Y}$ axis sunlight shadow tracing system, there are 4 $\mathrm{DC}$ motors. Two motor is used to control $\mathrm{X}$ axis and another motor is used to control $\mathrm{Y}$ axis. Output voltage from the sensor will be high when LRD under shadow. The objective is to design and implement an automated, $\mathrm{X}-\mathrm{Y}$ axis solar tracking mechanism using embedded system design in order to optimize the efficiency of overall solar energy output [7]. Two light dependent resistors (LDR) is used for each degree of freedom. LDRs are basically photocells that are sensitive to light. Software will be developed which would allow the microcontroller to detect and obtain its data from the two LDRs and then compare their resistance [8]. The four LDRs will be positioned in such a way, so that if one of the two comes under a shadow, the MCU will detect the difference in resistance and thus actuate the motor to move the solar panel at a position where the light upon both LDRs is equal. Two separate but identical circuits will be utilized for both axes and using Arduino to connect the LDR to system, we can check for the values coming from the LDR via the Arduino. To do this, connect the Arduino via USB to port and open up the 
Arduino IDE or software. Next, paste this code and upload it to Arduino:

Int sensorPin $=\mathrm{A} 0$; //LDR input connection

int sensorValue $=0$; // received sensor value

void $\operatorname{setup}()\{$

Serial.begin (..); //serial port for communication

\}

void $\operatorname{loop}()\{$

sensorValue $=$ AnalogRead with pin; //read the value from sensor

serial.printIn(sensor value); // prints the value from sensor to display

delay()

\}

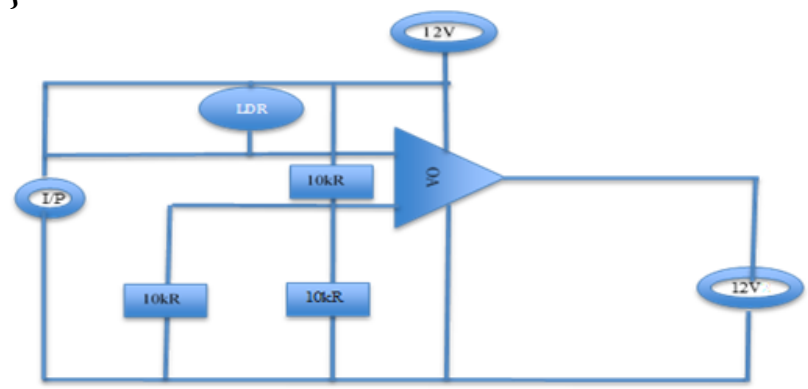

Figure 4. Comparator circuit with LDR

This paper is about moving the prototype along with the direction of sunlight; it uses a gear motor to control the position of the solar panel, which obtains its data from a microcontroller [9]. The objective is to design and implement an automated, XY axis solar shadow tracking mechanism using embedded system design in order to optimize the efficiency of overall solar energy output [9]. The flow diagram in Figure 5 represents the decision logic and software sequences used in open-loop control mode. In this mode, the Microcontroller uses the logic to verify day-night mode before monitoring the present position of the LDR and compare this to the output voltage calculated through the logic circuit. Positional correction to be required on any of the axes, the decision logic issues microcontroller commands for the DC motors on the relevant axes drives to move the solar collector system to the new position.

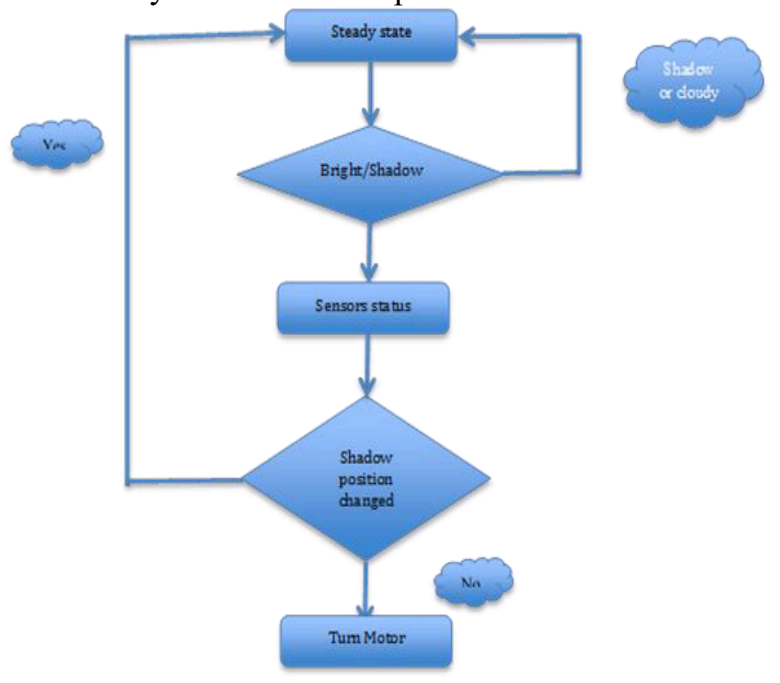

Figure 5. Flow diagram for microcontroller decision logic.
To develop the comprehensive system using five methodologies described below:

Principle 1: S1 under shadow, which is imply that output voltage $\mathrm{Vs} 1>\mathrm{Vs} 2$ or $\mathrm{Vs} 3$ or Vs4. we are using four op-amp comparator circuit for four LDR sensors. The individual circuit is basically an operational amplifier without feedback, that is, the op-amp is used in its open-loop configuration, and when the input voltage, Vs1 exceeds a pre-set reference voltage, $V_{\text {REF }}$ $(4.5 \mathrm{~V})$, the output changes state. Due to the very high openloop gain of the operational amplifier, using it with positive feedback or even with no feedback at all causes the output to saturate to its supply rail producing one of two distinct output voltages depending on the relative values of its two inputs.

In normal lighting conditions (no shadow), the one LDR receive the same amount of light, and the output of the operational amplifier has a low voltage level. When one of the LDR (on this case: R1) receives less light than the other, the voltage at the inverting input of operational amplifier, is lower than in the non-inverting input. When this happens, the voltage at the output of the operational amplifier goes high. The S1 has the low intensity of light imply on it thus producing a higher voltage output than the other sensors. In this project, the low intensity of light is fixed to 3.0 lux and the highest is at 13.0 lux. This condition is applicable for to principle 2, 3 \& 4 except for Principle 5 where the simulation is about to test the motor rotation if the intensity of light on each sensor is fixed to 3.0 lux. For principle 1, DC motors B \& D rotates in clockwise direction and DC motors A \& C stay with steady state condition, so B \& D motors allow to move prototype north side onwards if LRD (S1) seat under shadow.

Principle2: Let us consider that S2 under shadow, which is imply that output voltage Vs2>Vs1 or Vs3 or Vs4.

For principle 2, DC motors A \& $\mathrm{C}$ rotates in anticlockwise direction and DC motors B \& D stay with steady state condition, so A \& C motors allow to move prototype West side on words if LRD (S2) seat under shadow.

Principle2: consider S3 under shadow, which is imply that output voltage Vs3>Vs1 or Vs2 or Vs4.

For principle 3, DC motors $\mathrm{C} \& \mathrm{D}$ rotates in clockwise direction and DC motors A \& B stay with steady state condition, so A \& C motors allow to move prototype South side on words if LRD (S3) seat under shadow.

Principle4: consider S4 under shadow, which is imply that output voltage Vs4>Vs1 or Vs2 or Vs3.

For principle 4, DC motors A \& B rotates in anticlockwise direction and DC motors C \& D stay with steady state condition, so A \& B motors allow to move prototype North side on words if LRD (S4) seat under shadow.

Principle5: Let us consider that S1, S2, S3 \& S4 under shadow, which imply that output voltage from all LDR sensor are same $(\mathrm{Vs} 1=\mathrm{Vs} 2=\mathrm{Vs} 3=\mathrm{Vs} 4)$. Therefore, the DC motors A, B, C \& D stay at the same location instead of moving. 
This configure can be used to define motor rotation and specific direction of control system for the prototype:

Motor movement: east \& west side drive

Motor movement: north \& south side drive

Position lever use for up-down wheels position, according servo arm approaches set angle. \{

/* fire extinguisher prototype*/

DCmotor A \& B north = null;

DCmotor B \& D east = null;

DCmotor C \& D south = null;

DCmotor A \& C west = null;

Lever arm up = null;

Lever arm down = null;

// run wheel in active mode

eastwestpower $=-$ LDRsensor S1 \& S2;

northsouthpower $=$-LDRsensor S3 \& S4;

North A \& B set direction;

East B \& D set direction;

South C \& D set direction;

West A \& C set direction;

(.......

Different methods have been proposed to use the total force for prototype motion planning, the angle of the total force is used to design a PID controller to control $\theta$, and set the linear velocity as a positive value v. A simple controller is obtained to get the desired velocities $v_{x}$ and $v_{y}$

$$
\begin{gathered}
\mathbf{X}=\mathbf{v} \cos \boldsymbol{\theta} \\
\mathbf{Y}=\mathbf{v s i n} \boldsymbol{\theta} \\
\boldsymbol{\theta}=\boldsymbol{\omega} \\
{\left[\begin{array}{l}
x \\
y
\end{array}\right]=\mathrm{G}(\theta)\left[\begin{array}{l}
v \\
w
\end{array}\right]}
\end{gathered}
$$

Where $\mathrm{G}(\theta)=\left[\begin{array}{cc}\cos \theta & 0 \\ \sin \theta & 0\end{array}\right]$ and where $v_{x}$ and $v_{y}$ are the desired velocity on $\mathrm{x}$ and $\mathrm{y}$ axis respectively. With the state $\mathrm{q}=(\mathrm{x} ; \mathrm{y} ;)$ and where $(\mathrm{x} ; \mathrm{y})$ is the position in the plane of the midpoint of the axle connecting the rear wheels and $\theta$ denotes the direction angle measured anticlockwise from the $\mathrm{x}$-axis. The velocity control of the two front wheels determines the translation velocity of the robot $\mathrm{v}$ and the angular velocity $\omega$.

If $\|(x, y)\|<0.05$ then

$\mathrm{V}=0$ and $\omega=-\frac{\pi}{4} \times \theta$,

Or

$\mathrm{V}=0.1$ and $\omega={ }_{-} \frac{\pi}{4} \times[\theta-\varnothing(\mathrm{x}, \mathrm{y})]$,

$\varnothing(x, y)=\left\{\begin{array}{l}0 \\ \left(-\frac{\pi}{2}\right) \operatorname{sign}(y) \\ \tan ^{-1}\left(\frac{y}{x}\right)\end{array}\right\}$
This stabilizing opinion will prove, for any initial condition $q_{0}$, a decent estimate for the open-loop control.

The angular velocity, is able to solve energy saving solutions and produce smooth repulsive force in complex environment to avoid oscillations. As with torque, maximum joint angular velocity of each wheel occurs when the axis of the wheel is perpendicular to the direction of the total velocity of the base. Velocity of each of the four wheels can be expressed as:

$$
v_{i}=v_{c}+\theta^{*} \mathrm{k}^{*} w_{i}
$$

Where $v_{i}$ the speed vector of each wheels is, $v_{c}$ is the linear speed vector and $\theta$ is the angular rate of the device's frame in $\mathrm{x} \& \mathrm{y} . w_{i}$ is the distance vector of each wheel from the centre of the frame, and $\mathrm{k}$ is a unit vertical vector. It is to find the optimal control $U=[\mathrm{v}, \omega]$ for system and to minimize the following energy efficiency function:

$$
\mathrm{P}=\int_{t_{0}}^{t_{n}} E(U(t), \mathrm{q}(\mathrm{t}), \mathrm{t}) \mathrm{dt}
$$

Where $t_{0}$ is the initial time and $t_{n}$ final time to the destination respectively, $U=[v, \omega]$ and $q=[x, y, \theta] . E$ is a function of $U$ and $q$ which defines the energy using function to be minimized. E can be chosen in advance, and only needs to optimize $\mathrm{x}$ and $\mathrm{y}$ to obtain the optimal values of $\theta, v$ and $\omega$. At the same time we can correct the motor control values without control losing time. The design step following the movement direction is the synthesis of a feedback controller with the objective to keep solutions of the closed loop system as close as possible to the movement and to diminish effects of disturbances on the system behaviour, uncertainties in modelling, errors in parameter assessments. We reach a high efficiency through a continuous-time implementation which allows the use of adaptive timestep integrators.

\section{Conclusion}

The prototype was design to create curiosity and interest internally and externally for the product concept of our technology station at university of Johannesburg, South Africa. After completing the solar shadow tracker product development it is important to understand what more is left in the development process before the product can be industrialized. The X-Y axis movement solar shadow tracking are highly efficient in terms of the electrical energy output when compared to similar system. The main contributions of this work are the development of a two axis solar shadow tracker prototype that uses four sensors to predict the sun apparent position. In this system further research is needed to make the system more precise and complete.

\section{Reference}

1. M. David, "The solar energy tracker," $\mathrm{PhD}$ dissertation, University of Canterbury, New Zealand, 2008. 
2. Guo, R.; Dai, Q.; Hoiem, D. Single-image shadow detection and removal using paired regions. In Proceedings of the IEEE Conference on Computer Vision and Pattern Recognition, Providence, RI, USA, 20-25 June 2011; pp. 2033-2040.

3. Khan, S.H.; Bennamoun, M.; Sohel, F.; Togneri, R. Automatic feature learning for robust shadow detection. In Proceedings of the IEEE Conference on Computer

4. Prof. Pooja K. Chhatwani, Prof. Jayashree Somani, "Intelligent solar tracker system implemented on 8051 microcontroller". International Journal of Engineering Trends and Technology, Vol.4, Issue 9, pp 4267-4271, Sep.2013.

5. Deepthi. S, Ponni. A, Ranjitha. R, R. Dhanabal, "Comparison of efficiencies of single axis tracking system and dual axis tracking system with fixed mount". International Journal of Engineering Science and Innovation Technology (IJESIT), March 2013, vol.2, Issue 2, pp 425-430.

6. N.Othman,M.I.A.Manan,Z. Othman, S.A.M.AlJunid, "Performance Analysis of Dual-axis Solar Tracking System", IEEE International Conference on Control System, Computing and Engineering, 29 Nov. - 1 Dec. 2013, pp 370-375.

7. Poulek, V., Libra, M.. "A Very Simple Solar tracker for Space and Terrestrial Applications". Solar Energy Materials and Solar Cells. 2009. Pages 99101.

8. Luigi T.De Luca, Propulsion physics (EDP Sciences, Les Ulis, 2009)

9. F. De Lillo, F. Cecconi, G. Lacorata, A. Vulpiani, EPL, 84 (2008) 